\title{
COMO OS TURISTAS PERCEBEM OS ATRIBUTOS DE ATRATIVOS \\ TURÍSTICOS EM BONITO (MS)? \\ UMA ANÁLISE COM BASE EM COMENTÁRIOS PUBLICADOS NO TRIPADVISOR
}

\footnotetext{
Licença CC BY: Artigo distribuído sob os termos Creative Commons, permite uso e distribuição irrestrita em qualquer meio desde que o autor credite a fonte original.

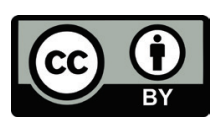
¿CÓMO LOS TURISTAS PERCIBEN LOS ATRIBUTOS DE ATRACTIVOS TURÍSTICOS EN BONITO/MS, BRASIL? UN ANÁLISIS CON BASE EN COMENTARIOS PUBLICADOS EN TRIPADVISOR

\section{MAURÍLIO BARBOSA DE OLIVEIRA DA SILVA'}

Universidade Federal de Mato Grosso do Sul, Campo Grande, Mato Grosso do Sul, Brasil

\section{DYEGO DE OLIVEIRA ARRUDA²}

Centro Federal de Educação Tecnológica Celso Suckow da Fonseca,

Rio de Janeiro, Rio de Janeiro, Brasil

\begin{abstract}
ÁLVARO GABRIEL ROMERO DE SOUZA ${ }^{3}$
Universidade Federal de Mato Grosso do Sul, Campo Grande, Mato Grosso do Sul, Brasil

MILTON AUGUSTO PASQUOTTO MARIANI ${ }^{4}$

Universidade Federal de Mato Grosso do Sul, Campo Grande, Mato Grosso do Sul, Brasil.
\end{abstract}


RESUMO: Ao partir da perspectiva de que é cada vez mais comum o hábito de os turistas compartilharem suas percepções na internet, o presente artigo tem como objetivo analisar os principais atributos valorizados por turistas que teceram comentários na página on-line do TripAdvisor acerca de atrativos turísticos visitados na cidade de Bonito/MS, um relevante destino turístico do Estado de Mato Grosso do Sul e do Brasil. Para atingir tal propósito, conduziu-se uma pesquisa de abordagem qualitativa, com amostragem crítica e calcada em princípios da netnografia. O estudo utilizou 360 comentários extraídos da página do TripAdvisor na internet, dos 26 atrativos listados como "as principais atrações" do território. De uma maneira geral, constatou-se que os turistas valorizam sobremaneira: as características gerais dos atrativos turísticos, com foco para as "práticas turísticas" que podem ser empreendidas no destino; detalhes do atendimento recebido nos empreendimentos do trade turístico do destino; as características dos serviços de alimentação oferecidos na localidade turística; além das especificidades do território no qual se localizam os atrativos turísticos.

PALAVRAS-CHAVE: Comportamento do turista. Netnografia. Iramuteq. Bonito/MS.

ABSTRACT: Based on the increasing tendency of tourists to share their perceptions on the internet, this article analyzes the main attributes valued by tourists who published their comments on the website TripAdvisor, in relation to the tourist attractions visited in the town of Bonito, an important ecotourism destination not only at state but also at national level. Qualitative research was conducted, with critical sampling based on principles of netnography. The study used 360 comments taken from the website TripAdvisor, relating to the 26 attractions listed as "the main attractions" of the region. In summary, the main aspects valued by the tourists were: the general characteristics of tourist attractions, with a focus on the "tourist practices" that can be carried out in the destination; details of the service provided by the enterprises of the tourism trade in the destination; characteristics of the food services offered in the tourist destination; and the specificities of the territory in which the tourist attractions are located.

KEY-WORDS: Tourist behavior. Netnography. Iramuteq. Bonito/MS, Brazil.

RESUMEN: A partir de la perspectiva de que es cada vez más común el hábito de los turistas compartir sus percepciones en la internet, el presente artículo tiene como objetivo analizar los principales atributos valorados por turistas que hicieron comentarios en la página on-line de TripAdvisor acerca de atractivos turísticos visitados en la ciudad de Bonito/MS, un relevante destino turístico del Estado de Mato Grosso do Sul y de Brasil. Para alcanzar tal propósito, se llevó a cabo una investigación de abordaje cualitativo, con muestreo crítico y calcado en principios de la netnografia. El estudio utilizó 360 comentarios extraídos de la página de TripAdvisor en internet, de los 26 atractivos listados como "las principales atracciones" del territorio. De una manera general, se constató que los turistas valoran: las características generales de los atractivos turísticos, con foco para las "prácticas turísticas" que pueden ser emprendidas en el destino; detalles del atendimiento recibido en los emprendimientos del trade turístico del destino; las características de los servicios de alimentación ofrecidos en la localidad turística; además de las especificidades del territorio donde se ubican los atractivos turísticos.

PALABRAS-CLAVE: Comportamiento del turista. Netnografia. Iramuteq. Bonito/MS. 


\section{INTRODUÇÃO}

O advento e a popularização da internet e das mídias sociais, contemporaneamente, representaram aos consumidores a oportunidade de oferecer suas opiniões às empresas e a outros consumidores por intermédio de comentários e publicações na web (Yilmaz, 2017). Essas opiniões, positivas ou negativas, perfazem revisões de produtos, de serviços e das próprias empresas numa dinâmica em que a disseminação dessa constante interação on-line entre consumidores e empresas faz parte do termo denominado "web 2.0" (Obeidat et al., 2017; Jablonska, 2017).

Em suma, a web 2.0 - também conhecida como "a rede social" - possibilitou interações bidirecionais, nas quais os consumidores, além de interagirem com as empresas, também geravam conteúdos e informações uns para os outros, não raro de modo colaborativo (Tavakoli \& Mura, 2018). Tal perspectiva representou uma evolução em relação à web 1.0, que era estática e, portanto, quase não permitia interação, fornecendo uma "via de mão única" no tráfego de informações, que eram carreadas de modo unidirecional das empresas para os consumidores (Patel, 2013). Contemporaneamente, o desafio - sobretudo por parte das empresas, com o advento da "web 3.0, 4.0 e até 5.0" - é processar grandes volumes de informações (big datas), gerando respostas personalizadas e "em tempo real" para os consumidores, melhorando suas experiências de consumo (Soava, 2015).

A escassez de informações é um fator que leva a muita dúvida na tomada de decisão por parte dos consumidores (Handel \& Schwartzstein, 2018). Assim sendo, para superar essa incerteza, o consumidor coleta informações, que estão disponíveis em abundância em sites especializados em revisões e análises críticas (Duffy, 2016).

As informações encontradas na web representam aspectos que, à ótica do consumidor (Brandt, Bendler \& Neumann, 2017): (a) minimizam os riscos e as incertezas em torno de um determinado bem ou serviço que o consumidor até então não conhece; (b) permitem com que o consumidor "se prepare" para que consiga consumir, sem muitos empecilhos, um determinado produto; e (c) fazem com que o consumidor anteveja detalhes de suas experiências de consumo numa dinâmica em que se evitam eventuais surpresas desagradáveis.

Sob o ponto de vista das empresas, deve-se ponderar que as informações disponibilizadas por consumidores na internet representam "entradas" (inputs) para os processos de planejamento organizacional, que podem implicar em novas estratégias que entreguem uma proposta de valor mais efetiva e adequada para os clientes (Kolb \& Thach, 2016; He, Wang \& Akula, 2017). Não obstante, para as empresas, a internet perfaz ainda um "campo de possibilidades" muito vasto para o estabelecimento de contatos efetivos, rápidos e personalizados com os consumidores (Malthouse et al., 2013).

As organizações do setor de turismo, em específico, pelo fato de atuarem em um segmento de mercado intensivo em informação, constantemente usam as plataformas digitais como mecanismos para a interação com os clientes, monitorando as percepções dos consumidores e gerando conteúdos que eventualmente os impactem (Leung et al., 2013). 
Nota-se que, por meio da internet, o turista consegue se "transportar" para a história, cultura, hábitos e costumes da região que pretenda visitar (Marujo, 2012). Em síntese, são comentários, avaliações, fotos, histórias e recomendações que são disponibilizados na internet e que permitem ao turista antecipar detalhes de suas experiências de viagem e, portanto, tomar alguma decisão de modo mais tranquilo e razoável (Noti, 2013; Leung et al., 2013).

Algumas páginas da internet - tais como TripAdvisor, Yelp, Booking, Hotel Urbano, Decolar e Expedia, só para citar alguns poucos exemplos - posicionam-se como ferramentas para proporcionar facilidades aos potenciais turistas, que conseguem fazer reservas, buscar informações, comparar preços, redigir comentários e ler as opiniões de outros turistas acerca de um determinado bem ou serviço (Mellinas, María-Dolores \& García, 2016).

O TripAdvisor, mais especificamente, surgiu no ano 2000 como um guia de viagens em que os próprios turistas podem emitir opiniões e, assim, alimentar o site com suas experiências em forma de avaliações e comentários. Atualmente, a página, além de se posicionar como um dos mais relevantes portais da internet para a interação entre turistas e organizações do setor de turismo e hotelaria, possui mais de 600 milhões de avaliações e comentários redigidos por turistas, que conseguem "conhecer" detalhes dos atributos de quase 8 milhões de equipamentos de apoio ao turismo (tais como acomodações, atrações turísticas e restaurantes), numa dinâmica em que os visitantes que navegam pelo site passam dos 456 milhões por mês (TripAdvisor, 2018).

Em síntese, o TripAdvisor é uma fonte de relevantes feedbacks acerca de pontos turísticos (zoológicos, montanhas, praias, parques, monumentos, construções arquitetônicas, locais religiosos e afins), numa dinâmica em que é possível que se depreendam aspectos quanto à qualidade, à segurança, ao acesso e à comodidade da atração, a depender do modo como os consumidores avaliam e tecem comentários, levando em conta os vários atributos dos atrativos turísticos com os quais interagem (Medeiros et al., 2018).

Parte-se da perspectiva de que os comentários publicados por consumidores na página on-line do TripAdvisor são relevantes inputs para reflexões protagonizadas por ferramentas de pesquisa, tais como a netnografia - que é um tipo de etnografia realizada em ambientes on-line, em que, a partir do conteúdo "trocado" pelas pessoas na internet, é possível se inferir detalhes acerca de suas percepções e, por conseguinte, de seu comportamento de consumo (Adade, Barros e Costa, 2018; Toledano, 2017). De todo modo, quais os principais atributos, dos atrativos turísticos visitados, que são valorizados pelos turistas e que aparecem nos comentários publicados na página on-line do TripAdvisor?

Com base na supracitada problemática de pesquisa, o presente artigo tem como objetivo analisar os detalhes em torno dos principais atributos valorizados pelos turistas que teceram comentários, no TripAdvisor, acerca de atrativos turísticos visitados na cidade de Bonito, no Estado de Mato Grosso do Sul.

A escolha de Bonito como lócus das análises do presente estudo deve-se ao fato de que a cidade é um dos principais destinos turísticos do Estado de Mato Grosso do Sul, sendo considerado, pelo Ministério do Turismo, um dos destinos indutores da atividade turística no país (Barbosa, 2015). De acordo com dados do Inventário Turístico de Bonito e Região, o destino turístico sob análise recebeu, em 2017, um quantitativo de turistas 5,5\% 
menor em relação aos números consolidados em 2016 (OTEB, 2017). Não obstante, o principal atrativo turístico do território, a Gruta do Lago Azul, também sofreu retração de 7\% no número de visitas no mesmo período (2017/2016), o que sugere a necessidade de se empreender esforços para atrair mais turistas aos atrativos turísticos de Bonito/MS, numa dinâmica em que conhecer as principais percepções e avaliações dos consumidores em plataformas on-line (tais como o TripAdvisor) é um expediente crucial para a criação de estratégias organizacionais que objetivem entregar uma proposta de valor mais adequada aos turistas (Klein et al., 2011; OTEB, 2017).

Nesse ínterim, destaque-se que a importância do presente estudo, do ponto de vista empírico, reside na possibilidade de sugerir insights para que os responsáveis por atrativos turísticos, de um modo geral, e pelo segmento turístico de Bonito, mais especificamente, possam criar estratégias para entregar uma melhor proposta de valor aos turistas, com base nos atributos por estes valorizados e manifestados em comentários no TripAdvisor. Não obstante, do ponto de vista teórico, o artigo em questão posiciona-se como um trabalho que analisa detalhes de como os consumidores manifestam-se e geram conteúdos e comentários na internet - o que são assuntos emergentes na literatura especializada na área de turismo.

\section{MARCO TEÓRICO}

\section{O COMPORTAMENTO DO TURISTA NA INTERNET: ALGUMAS REFLEXÕES}

O termo "web 2.0" surgiu na primeira metade dos anos 2000, com o propósito de designar um conjunto de plataformas digitais que, para além da multiplicidade de informações, em tempo real, que disponibilizaram às pessoas, também permitiram com que os usuários fossem geradores de conteúdo numa dinâmica em que os internautas conseguem postar imagens e comentários na web, fazer avaliações, emitir pareceres, indicar bens, serviços e lugares, de tal modo que os usuários influenciam uns aos outros na internet e estabelecem interações constantemente (Wirtz, Schilke \& Ullrich, 2010).

O chamado "turista 2.0" - termo que se popularizou a partir do advento do fenômeno da web 2.0 - é alguém preocupado em saber, antes de chegar ao destino, os detalhes e as condições daquilo que o espera (Fino et al., 2013). Assim sendo, esse tipo de turista ancora as suas percepções e decisões em textos, mapas, imagens (postadas em redes sociais, tais como o Instagram e Facebook) e vídeos, principalmente produzidos por outros turistas, em que exista uma descrição fidedigna do modo como a prática turística no destino se desenrolará, com as reais conjecturas daquilo que o atrativo efetivamente oferece (Jiménez, 2012; Zucco et al., 2018).

A tarefa de planejar uma viagem, sobretudo em períodos de férias e envolvendo os membros da família, é algo cercado de muita pressão e responsabilidade, numa dinâmica em que os turistas tentam se cercar de informações as mais reais e sinceras possíveis informações essas que, não raro, advêm de outros consumidores, por intermédio das redes sociais e plataformas de compartilhamento de avaliações e comentários sobre equipamentos de apoio ao turismo (tais como o TripAdvisor) (Cox et al., 2009). 
Além de comparar preços, traçar rotas eescolher as melhores formas de deslocamento, os turistas conectados à internet usam as plataformas digitais para (Jacobsen \& Munar, 2012):

Optar pelas atividades que serão empreendidas no destino ao longo do período da visita: os turistas, no geral, realizam uma busca para tentarem planejar "o que fazer", quais atrativos visitar e o que é indispensável de se conhecer ao longo da viagem;

- Escolher as acomodações em que se hospedarão: há uma tentativa de se antever os detalhes gerais da acomodação, a qualidade das instalações, a diversidade dos serviços eventualmente ofertados, a proximidade em relação aos principais atrativos turísticos do destino, além de aspectos relativos à segurança do local;

- Escolher restaurantes e locais em que se alimentarão: nesse ínterim, os turistas, no geral, tentam comparar os preços das opções de alimentação, além de vasculhar os locais que servem alimentos típicos dos locais em que a visita esteja ocorrendo;

- Buscar informações acerca de agências de viagem e/ou operadoras de turismo: há uma busca quanto aos detalhes de possíveis pacotes de viagens para o destino pretendido, os quais eventualmente agreguem um conjunto de serviços e funcionalidades à atividade turística (tais como transporte, acesso a alguns atrativos e hospedagem a um preço mais acessível).

- Além de buscar informações de modo intenso na internet, os turistas, contemporaneamente, também possuem a necessidade de compartilhar imagens, avaliações e comentários sobre as viagens que realizaram (Munar \& Jacobsen, 2014).

Em suma, pode-se depreender que os turistas compartilham informações na internet sobretudo porque (Munar \& Jacobsen, 2014; Chung \& Koo, 2015): (a) há uma tentativa de se obter maior capital social (ou seja, maior quantidade de contatos e "amigos" nas plataformas on-line e redes sociais) na medida em que se expõem, na web, os detalhes e as imagens da última viagem; (b) os turistas "sentem-se bem" ao postarem as características da viagem na internet - há uma necessidade de cunho emocional em torno de tal expediente, portanto; (c) objetiva-se resolver eventuais problemas, sobretudo quando ocorreu algo de errado ao longo da viagem, que resultou em altos níveis de insatisfação (acredita-se, nesse ínterim, que os comentários negativos postados na internet perfazem "fontes de pressão" para que as organizações resolvam eventuais problemas, não solucionados presencialmente); e (d) há uma tentativa de auxiliar as demais pessoas (outros turistas) a tomarem decisões, sobretudo a partir de eventuais experiências negativas pelas quais passaram os turistas que resolvem comentar e avaliar tais aspectos nas plataformas on-line.

Jacobsen e Munar (2012), ao explorarem detalhes do comportamento do turista ante a difusão do acesso e uso da internet, ponderam que os turistas, ao compartilharem informações e buscarem na web referências sobre equipamentos de apoio ao turismo, estão majoritariamente preocupados em antever os detalhes de como será a sua experiência ao longo de suas viagens. Essa preocupação, em síntese, deve-se à percepção de que tais equipamentos de apoio ao turismo são essenciais para que o turista consiga se "sentir bem" e aproveitar a sua viagem no destino pretendido.

Uma das principais fontes de informações sobre os atributos dos atrativos turísticos é o TripAdvisor, cada vez mais utilizado também pelas empresas por representar um 
marketing digital de baixo custo. Apesar de existirem outras plataformas on-line (tais como Yelp e Expedia) para o compartilhamento e a busca de informações sobre os atributos das atrações turísticas, percebe-se que o TripAdvisor se posiciona como uma plataforma premium, principalmente por possuir uma grande base de dados, além de uma página de fácil navegação (Miranda, Souza \& Demo, 2018; Xiang et al., 2017).

No tópico que segue há uma tentativa de se explorar os atributos valorizados pelos consumidores de atrativos turísticos, com destaque para os estudos que analisaram as percepções e as avaliações de turistas postadas na internet.

\section{ATRIBUTOS DOS ATRATIVOS TURÍSTICOS: O QUE OS TURISTAS VALORIZAM?}

Os atrativos turísticos, em suma, integram a oferta turística de um determinado destino e representam um dos principais fatores que fazem com que os turistas se desloquem de seus locais de residência habitual, com o propósito de acumular experiências e conhecer novas culturas, paisagens, modos de vida e curiosidades (Travesi, 2017).

O objetivo primordial dos atrativos turísticos é proporcionar lazer e entretenimento aos turistas, permitindo com que os visitantes consigam exercer atividades distintas daquelas que realizam cotidianamente em uma perspectiva marcadamente hedônica e experiencial (Manosso et al., 2015; Botti, Peypoch \& Solonandrasana, 2007).

Leiper (1990) sugere que nem todo atrativo tem a mesma importância para o turista, podendo ser objeto de uma classificação hierárquica que distingue as atrações entre primárias, secundárias e terciárias. As atrações primárias, em suma, exercem um papel decisivo na escolha de um determinado destino pelo turista, o que implica em considerar que tal atrativo deve ser estimulante o suficiente para que o potencial visitante saia de sua "zona de conforto" e decida empreender esforços para conhecer o destino turístico sob análise. As atrações secundárias, por seu turno, são aquelas que já são (re)conhecidas pelos visitantes, mas que não possuem um peso significativo na definição do roteiro a ser empreendido pelo turista. Por fim, as atrações terciárias perfazem aquelas que são desconhecidas pelos visitantes antes da chegada no destino, mas que agregam elementos importantes na experiência turística do visitante após serem "descobertas".

Ao identificarem atributos de qualidade que são recorrentes nos comentários de turistas de importantes destinos turísticos brasileiros, Mondo e Fiates (2016), valendo-se de uma pesquisa de caráter netnográfico, pontuam que os aspectos mais relevantes são: (a) localização e acesso, que devem permitir aos visitantes deslocamentos rápidos e práticos; (b) estética e infraestrutura dos atrativos, de tal modo que tais aspectos sejam coerentes em relação às especificidades naturais e socioculturais do destino turístico; (c) segurança, que engloba tanto a segurança do atrativo em si quanto da cidade ou região que o cerca; (d) custo-benefício - se o valor cobrado condiz com todos os aspectos de localização, estética, infraestrutura, segurança e atendimento do atrativo sob análise; (e) condições climáticas, muito valorizadas principalmente em atrativos que envolvem contato permanente com a natureza; e ( $\mathrm{f}$ ) atendimento ao cliente, que inclui polidez, educação e proatividade dos colaboradores dos empreendimentos turísticos. 
Em suma, faz-se necessário esclarecer que a netnografia, utilizada no supracitado estudo de Mondo e Fiates (2016), perfaz um método qualitativo calcado em princípios da etnografia "clássica", muito útil para a coleta, sistematização e análise de dados disponíveis em ambientes on-line (Polivanov, 2013; Costello, McDermott \& Wallace, 2017). Kozinets (2002, p. 62) esclarece que a netnografia representa "(..) uma nova metodologia de pesquisa qualitativa, que adapta técnicas de pesquisa da etnografia para estudar as culturas e comunidades que estão emergindo através de comunicações mediadas pelo computador".

Percebe-se que a netnografia, ao ser utilizada como método de pesquisa, embasa-se fundamentalmente no expediente da observação participante, ou seja: o pesquisador, por meio de uma maior ou menor intervenção nas páginas e nas comunidades on-line, tenta captar e sistematizar informações que lhe permitam compreender os detalhes das interações sociais na rede, não raro por meio de paradigmas epistemológicos de diversos campos, como a antropologia, a sociologia e os estudos culturais (Polivanov, 2013; Kozinets, 2014).

Posts, comentários, revisões, análises, réplicas, tréplicas, spams e até comentários trolls - feito por indivíduos interessados em "tumultuar" a discussão corrente por meio de humor duvidoso e/ou frases politicamente incorretas - perfazem os elementos basilares da netnografia, pois compõem as informações substanciais capazes de sinalizar as percepções dos indivíduos e o modo como eles se comportam na web e até mesmo fora dela (Schuman, Lawrence \& Pope, 2018).

Não obstante, alheio ao estudo netnográfico e notadamente focado em revelar as percepções de turistas quanto aos atrativos turísticos que visitam, Subhiksu, Ardika e Madiun (2015) detectaram que os principais atributos valorizados por turistas que frequentaram museus são: (a) arquitetura dos museus, que por localizarem-se normalmente em prédios históricos, já é responsável por boa parte da atração; (b) coleção disponível para visitação, de tal modo que a chegada de novas peças é uma estratégia para renovação do público; (c) layout, responsável pelo potencial dinamismo do circuito a ser percorrido no museu; (d) qualidade do serviço, que inclui a proatividade e a polidez da equipe de colaboradores do atrativo; (e) limpeza das instalações; ( $\mathrm{f}$ ) beleza das pinturas, quadros, instalações, esculturas e afins; e (g) hospitalidade, refletida no "receber bem" por parte da equipe de colabores do museu e da própria comunidade do território no qual o empreendimento está localizado.

Mustelier-Puig, Anjum e Ming (2018), por seu turno, detectaram que existe uma relação bastante consistente entre a qualidade dos atributos do atrativo turístico e a percepção de satisfação dos turistas - quanto maiores as crenças de que o atrativo é de qualidade, mais expressivos e positivos serão níveis de satisfação manifestados pelos visitantes. Ademais, ainda segundo os supracitados autores, os principais atributos que impactam na percepção de qualidade dos atrativos turísticos são: (a) o conhecimento do colaborador acerca dos detalhes e da história do produto turístico ofertado; (b) a atitude do colaborador, o que engloba a percepção de qualidade quanto aos detalhes do atendimento oferecido aos visitantes; (c) o comportamento não verbal do colaborador, tais como a proatividade e a educação manifestadas pelos funcionários; e (d) conhecimento de outros idiomas (sobretudo o inglês), que facilite a comunicação entre os representantes do atrativo e os turistas provenientes de outros países. 
Detendo-se nas percepções de visitantes de destinos turísticos considerados "amigáveis", percebe-se que os principais atributos valorizados pelos turistas são os seguintes (Anuar et al., 2014): (a) os detalhes, a beleza e a diversidade dos recursos naturais - tais como cachoeiras, praias, vida selvagem e afins; (b) a qualidade dos serviços oferecidos no atrativo; (c) a liberdade de escolha, que pode ser traduzida como o poder de escolher o que fazer e quando fazer; (d) a hospitalidade, compreendida como a sensação de acolhimento percebida pelo turista no destino visitado; e (e) o envolvimento, que agrega todos os atributos pontuados para que o turista participe ativamente da "produção" do produto turístico.

Em Mato Grosso do Sul, Mariani, Barboza e Arruda (2012), ao avaliarem o grau de satisfação dos turistas com os atrativos turísticos de Jardim, município que integra o Parque Nacional da Serra da Bodoquena, em Mato Grosso do Sul (mesmo território em que está localizado o destino turístico de Bonito/MS), preconizam que os atributos mais bem avaliados pelos visitantes são os seguintes: (a) hospitalidade; (b) limpeza e higiene das instalações; (c) cuidados ambientais, muito valorizados por turistas que dão preferência a passeios ecológicos - que perfazem a maioria dos produtos turísticos ofertados na localidade; (d) custos dos atrativos; (e) aparato de saúde pública do território em que o destino turístico se localiza; e (f) sinalização dos atrativos.

Em uma tentativa de compreender as percepções de turistas australianos, Pearce e Wu (2014), valendo-se de comentários disponibilizados na página on-linedo TripAdvisor, detectaram que os principais aspectos valorizados são: (a) história do atrativo visitado; (b) habilidade do guia turístico em reproduzir os detalhes e as histórias dos atrativos; (c) características físicas dos atrativos (beleza cênica, estrutura, conservação e afins); e (d) custo-benefício dos destinos turísticos visitados.

Detendo-se nas avaliações de turistas internacionais na China, também com base nos comentários postados na página do TripAdvisor, Wu, Wall e Pearce (2014) descobriram que os atributos mais relevantes à ótica dos turistas pesquisados são: (a) preço dos produtos turísticos; (b) qualidade e variedade dos produtos; e (c) aspectos hedônicos inerentes à visita ao destino turístico, relacionados, portanto, à ideia de diversão e prazer. Em síntese, o Quadro 1 sumariza os principais atributos valorizados pelos turistas acerca dos atrativos turísticos visitados, conforme a revisão de literatura brevemente sumarizada neste tópico.

Quadro 1: Principais atributos valorizados pelos turistas acerca dos atrativos turísticos visitados

\begin{tabular}{|l|l|l|l|}
\hline Foco do estudo & $\begin{array}{l}\text { Instrumento de } \\
\text { pesquisa }\end{array}$ & Atributos valorizados pelos turistas & Referência \\
\hline $\begin{array}{l}\text { Turistas de } \\
\text { importantes destinos } \\
\text { turísticos do Brasil }\end{array}$ & Netnografia & $\begin{array}{l}\text { Localização e acesso; estética e } \\
\text { infraestrutura; segurança; custo-benefício; } \\
\text { condições climáticas; atendimento ao } \\
\text { cliente }\end{array}$ & $\begin{array}{l}\text { Mondo e Fiates } \\
(2016)\end{array}$ \\
\hline Turistas de museus & $\begin{array}{l}\text { Observação direta, } \\
\text { entrevistas e } \\
\text { questionários }\end{array}$ & $\begin{array}{l}\text { Arquitetura; coleção disponível para } \\
\text { visitação; layout; qualidade do serviço; } \\
\text { limpeza; beleza; hospitalidade }\end{array}$ & $\begin{array}{l}\text { Subhiksu, Ardika } \\
\text { e Madiun (2015) }\end{array}$ \\
\hline $\begin{array}{l}\text { Turistas de um modo } \\
\text { geral }\end{array}$ & Questionários & $\begin{array}{l}\text { Conhecimento do colaborador do atrativo; } \\
\text { atitude do colaborador; comportamento } \\
\text { não verbal do colaborador; conhecimento } \\
\text { de outros idiomas por parte do colaborador }\end{array}$ & $\begin{array}{l}\text { Mujum e Ming } \\
\text { (2018) }\end{array}$ \\
\hline
\end{tabular}




\begin{tabular}{|l|l|l|l|}
\hline $\begin{array}{l}\text { Turistas de destinos } \\
\text { turísticos "amigáveis" }\end{array}$ & Entrevistas & $\begin{array}{l}\text { Detalhes, beleza e diversidade dos } \\
\text { recursos naturais; qualidade dos serviços; } \\
\text { liberdade de escolha; hospitalidade; } \\
\text { envolvimento }\end{array}$ & $\begin{array}{l}\text { Anuar et al. } \\
(2014)\end{array}$ \\
\hline $\begin{array}{l}\text { Turistas de um } \\
\text { destino turístico do } \\
\text { Mato Grosso do Sul }\end{array}$ & Entrevistas & $\begin{array}{l}\text { Hospitalidade; limpeza e higiene; } \\
\text { cuidados ambientais; custos dos atrativos; } \\
\text { aparato de saúde pública do território; } \\
\text { sinalização dos atrativos }\end{array}$ & $\begin{array}{l}\text { Mariani, Barboza } \\
\text { e Arruda (2012) }\end{array}$ \\
\hline Turistas australianos & $\begin{array}{l}\text { Análise de } \\
\text { comentários on-line }\end{array}$ & $\begin{array}{l}\text { História do atrativo; habilidade do } \\
\text { guia turístico; características físicas dos } \\
\text { atrativos; custo-benefício dos destinos }\end{array}$ & $\begin{array}{l}\text { Pearce e Wu } \\
\text { (2014) }\end{array}$ \\
\hline $\begin{array}{l}\text { Turistas } \\
\text { internacionais na } \\
\text { China }\end{array}$ & $\begin{array}{l}\text { Análise de } \\
\text { comentários on-line }\end{array}$ & $\begin{array}{l}\text { Preço dos produtos turísticos; qualidade } \\
\text { e variedade dos produtos; aspectos } \\
\text { hedônicos }\end{array}$ & $\begin{array}{l}\text { Wu, Wall e } \\
\text { Pearce (2014) }\end{array}$ \\
\hline
\end{tabular}

Fonte: Elaborado pelos autores, com base na revisão de literatura.

De uma maneira geral depreende-se, a partir das discussões teóricas do presente artigo, que os turistas, no geral, valorizam atributos principalmente relacionados: (a) aos aspectos físicos dos atrativos turísticos (tais como infraestrutura, layout, segurança e sinalização - só para citar alguns poucos exemplos); (b) ao comportamento dos colaboradores dos empreendimentos turísticos; (c) às características do território no qual o atrativo turístico esteja localizado (aparato de saúde da localidade, segurança do território e afins); (d) além da hospitalidade e dos aspectos hedônicos inerentes ao contato com os detalhes do atrativo turístico efetivamente visitado.

Porém, será que o conjunto de atributos pontuados aparece nas "falas" dos turistas que teceram comentários na página on-line do TripAdvisor acerca dos atrativos turísticos do destino de Bonito, no Mato Grosso do Sul? Enfim, no tópico que segue, apresentamse os procedimentos metodológicos do presente estudo, em que se objetivou apresentar elementos que permitam uma reflexão em torno da supracitada pergunta.

\section{METODOLOGIA}

O presente artigo apresenta uma abordagem qualitativa, em que princípios da netnografia foram utilizados para a coleta, sistematização e análise de informações disponibilizadas por turistas na internet na página on-line do TripAdvisor.

Kozinets (2014) pontua que há três tipos de dados (informações) que podem ser coletadas por intermédio do uso da netnografia: (a) dados arquivais, que são aqueles que o pesquisador retira diretamente de comunicações preexistentes, cujas criação ou estimulação não ficam a cargo dele [pesquisador]; (b) dados extraídos, que são aqueles que o pesquisador cria em conjunção com a comunidade on-line, por meio de interação pessoal e comunal; e (c) dados de notas de campo, que são as anotações que o próprio pesquisador registra de suas observações da comunidade, seus membros e a interação estabelecida entre esses membros.

Deve-se salientar que o presente estudo se baseou principalmente em dados arquivais - conforme classificação de Kozinets (2014), anteriormente descrita -, extraídos de comentários postados na página do TripAdvisor no período de janeiro a dezembro de 
2017. Vale ponderar, por ser oportuno, que todos os comentários foram provenientes de avaliações quanto a atributos dos atrativos turísticos da cidade de Bonito, um relevante destino indutor do turismo no Estado do Mato Grosso do Sul e no Brasil.

A extração dos dados que subsidiaram o presente estudo da página do TripAdvisor ocorreu de modo manual, ou seja: providenciou-se a leitura atenta de cada comentário dos turistas que visitaram atrativos turísticos de Bonito/MS, com o consequente "copia e cola" dos comentários mais relevantes, que foram analisados com o uso do software Iramuteq conforme se detalhará mais adiante neste tópico. Em suma, essa dinâmica mais "manual" de trabalho relegou aos pesquisadores a oportunidade de uma "vivência" no âmbito da página do TripAdvisor, de tal modo que esse contato foi útil para análises e inferências conduzidas no estudo, com o uso de princípios da netnografia.

No planejamento da pesquisa, definiu-se a amostra de comentários selecionados como sendo crítica. Em síntese, tal forma de amostragem é não probabilística e caracteriza-se pela escolha de um pequeno número de casos mais ilustrativos, ou seja: no estudo, primou-se pela análise de comentários mais consubstanciados e detalhados, que foram selecionados para se "produzir mais informação e ter o maior impacto no desenvolvimento do conhecimento" (Patton, 2002, p. 276).

A perspectiva a partir da qual os pesquisadores "adentraram" na página do TripAdvisor foi passiva - nessa abordagem, não há uma preocupação em se relevar a identidade do pesquisador e nem os propósitos da pesquisa aos participantes on-line (Mkono, 2012).

O estudo teve como foco os comentários acerca de 26 atrativos turísticos de Bonito/ MS, descritos no TripAdvisor como "as principais atrações" do território. Nesse grupo, encontram-se atrativos de destaque como a Gruta do Lago Azul e o Rio da Prata, conhecidos por suas águas azuis e cristalinas. Os aspectos que foram incluídos nas análises no escopo do presente artigo foram: (a) nota geral do atrativo; (b) nota individual atribuída pelo autor da resenha; (c) local de origem do viajante - quando disponível; (d) resenha; (e) respostas do próprio atrativo - quando disponível; ( $f$ ) fotos que ilustram os perfis das atrações e fotos postadas pelos próprios turistas; (g) número de contribuições anteriores do autor da resenha; e (h) quantidade de "votos úteis" que o autor recebeu ao longo de suas análises, ou seja: quantas vezes suas resenhas foram indicadas como úteis por outros usuários. Todos esses aspectos auxiliaram na composição do "quadro analítico final" do trabalho, embora o foco tenha recaído sobre os textos dos comentários.

Foram analisados, ao todo, 360 comentários, com 38.197 verbetes (palavras), que a partir de uma organização prévia (preparação de um "corpus textual") foram submetidos ao software Iramuteq, que processou os textos, realizou contagem da frequência absoluta de palavras, gerou imagens gráficas das palavras mais recorrentes nos comentários avaliados, além de sugerir palavras e termos mais fortemente relacionados uns com os outros ao longo dos comentários dos turistas na internet na página do TripAdvisor.

O Iramuteq é um software gratuito e desenvolvido sob a lógica do opensource; ele ancora-se no ambiente do software estatístico $\mathrm{R}$, e permite a realização de análises gerais de textos. Em resumo, por possuir uma interface com o software R, o Iramuteq representa uma oportunidade para que sejam empreendidas formas de análises estatísticas de textos qualitativos, produzidos por meio de entrevistas em profundidade, relatórios e documentos diversos (Souza et al., 2018). 
Deve-se ponderar que o uso de softwares - tais como o Iramuteq - na condução de pesquisas qualitativas e na análise de dados textuais é algo muito útil, sobretudo porque permite uma fácil organização e sistematização das informações, facilitando todo o processo de investigação, análises e discussões inerentes à pesquisa a partir dos dados coletados (Camargo \& Justo, 2013).

O Iramuteq é capaz de trazer informações lexográficas, que também incluem estatísticas básicas, como frequência e quantidade de palavras; e outras funções mais avançadas, tais como: (a) a Análise Fatorial de Correspondência (AFC), que permite a elaboração de clusters de palavras mais fortemente correlacionadas; (b) a Classificação Hierárquica Descendente (CHD), que apresenta um teste de hipótese a partir de certa probabilidade e de uma estatística qui-quadrado quanto ao nível de correlação dos termos em determinados clusters (classes de palavras); (c) a Análise de similitude, que permite uma maior compreensão de como as palavras recorrentes estão sendo relacionadas com outras palavras dentro do texto; e (e) a Nuvem de Palavras, que mostra, de forma gráfica, as palavras que mais se destacaram ao longo do corpus textual.

Registre-se, por ser oportuno, que o uso do software Iramuteq como ferramenta para a análise de dados textuais ainda é algo muito incipiente nas pesquisas no Brasil (Camargo \& Justo, 2013). Muito embora o uso da supracitada ferramenta tenha obtido, desde 2013, uma ligeira relevância nos estudos da área da saúde pública brasileira, ressalte-se que ainda são embrionários os esforços do uso do Iramuteq nas pesquisas e nas reflexões na área do turismo e da hospitalidade, especificamente - o que faz com que o presente artigo ganhe um caráter inédito e original.

Portanto, com base nos procedimentos delineados, foram feitas as principais constatações e inferências do estudo, conforme descritas no tópico que segue.

\section{RESULTADOS}

\section{Como os tURISTAS "ENXERgam" os atrativos turísticos?}

Na medida em que os visitantes publicam comentários na página do TripAdvisor, é comum que seja feita - pelos próprios turistas - uma avaliação geral do atrativo sujeito ao comentário por meio da atribuição de uma nota, em uma escala que vai de 1 (a pior avaliação possível) até 5 (a melhor avaliação).

Em suma, deve-se ponderar que a análise de resultados do presente artigo concentrouse nos comentários acerca de atrativos turísticos cuja avaliação geral gravitou entre 3 e 5, uma vez que não foi detectado um conjunto significativo de empreendimentos cuja nota, na página do TripAdvisor, fosse inferior a 3.

Após o processamento do software Iramuteq, o primeiro output a ser analisado, neste artigo, é a nuvem de palavras (Figura 1). Os advérbios "super", "muito" e "não" foram omitidos da nuvem de palavras por não representarem, por si só, nesta figura, uma informação relevante. 


\section{TURISM曲}

Figura 1: Nuvem de palavras decorrentes dos comentários sobre atrativos turístico.

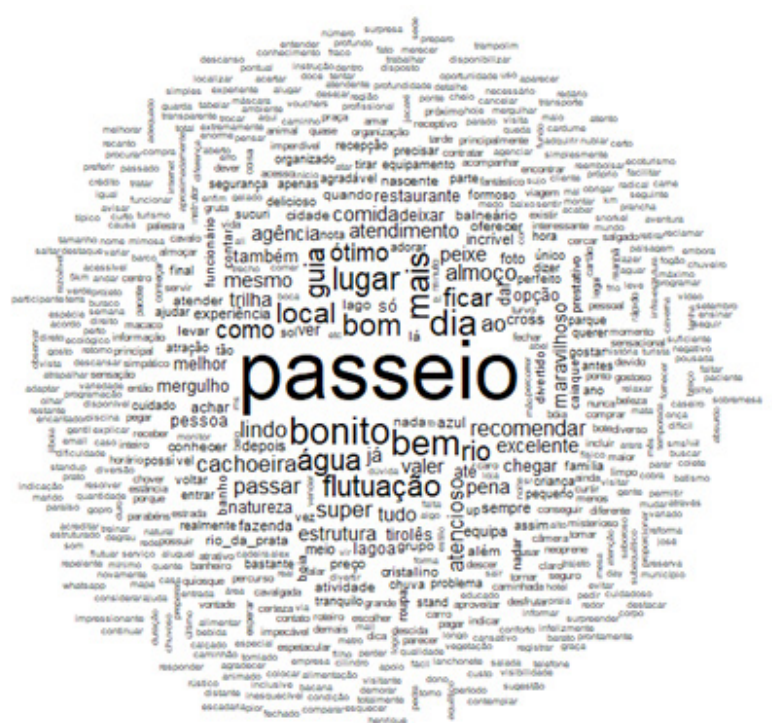

Fonte: Elaborada pelos autores a partir dos dados da pesquisa

Percebe-se, ao se observar a nuvem de palavras, que o termo "passeio" é recorrente na fala dos turistas, o que faz com que tal verbete apareça com ênfase na Figura 1. Em suma, o foco na palavra "passeio" revela que o turista que vai a Bonito, no geral, está interessado em conhecer o território, circulando pelos atrativos existentes na localidade, numa perspectiva hedônica que remete à ideia de férias, recreação, lazer, contemplação, busca de sensações e aventura. Destaque-se que as supracitadas inferências são coerentes com as ponderações de Manosso et al. (2015) e Botti, Peypoch e Solonandrasana (2007), que sugerem que os turistas "buscam" os passeios e os atrativos turísticos sobretudo em função da necessidade de acumular sensações e experiências.

Ainda com foco na nuvem de palavras, constata-se a ênfase de termos que remetem a particularidades dos passeios de Bonito, tais como: "flutuação", "água", "cachoeira" e "natureza". Tais palavras reforçam o potencial do ecoturismo no município de Bonito, principalmente no que tange à "água" como elemento alusivo à natureza e que traz singularidade à prática turística no território sob análise - boa parte dos "passeios" de Bonito envolvem o contato direto e/ou a contemplação de aspectos da "água", o que coloca os atrativos que "possuem água" como atrações primárias do território, conforme classificação de Leiper (1990). Vale ressaltar ainda que, ao longo da pesquisa, percebeu-se que as imagens divulgadas, tanto por turistas quanto pelos próprios atrativos em suas estratégias de marketing, remetem muito à presença da natureza e, por conseguinte, da água como elementos predominantes da paisagem do território.

Ademais, constatou-se, nas imersões na página do TripAdvisor, que termos que aparecem na nuvem de palavras são demasiadamente explorados nas descrições dos atrativos turísticos no site. Embora nem todos os atrativos tenham o campo "sobre" (espaço reservado para a descrição do local pelos gestores do atrativo) preenchido, os que o fazem têm a noção de que a água e os passeios que nela se realizam (tais como flutuação, mergulho, além da mera contemplação) são substanciais pontos de interesse pelo consumidor. $\mathrm{O}$ trecho a 
seguir, extraído da descrição de um dos atrativos do território, ilustra a supracitada inferência: "Águas cristalinas, profundidade desconhecida, visibilidade de mais de 40 metros, passeios de flutuação e mergulho com cilindro."

De todo modo, vale ponderar que nas imersões no TripAdvisor percebeu-se que alguns atrativos administram mal o processo de interação com os turistas nas plataformas digitais. Em algumas circunstâncias, há uma demora no oferecimento de respostas a eventuais problemas e/ou dúvidas manifestados pelo consumidor; ao passo que também há pouca proatividade, por parte dos atrativos, em oferecer instruções aos turistas acerca de como a "prática turística" se desenvolve no território. Os supracitados aspectos são endêmicos principalmente nos atrativos turísticos administrados pelo poder público local - como a Gruta do Lago Azul, que é um atrativo gerido pelo município.

Também foram consideráveis as menções ao atendimento dos colaboradores que atuam nos atrativos turísticos, em especial do guia turístico - as palavras "guia", "atendimento" e "atencioso" ilustram a importância relegada a esse aspecto, corroborando os estudos de Pearce e Wu (2014), além de Mustelier-Puig, Anjum e Ming (2018).

Por fim, deve-se destacar que, ainda que atributos ligados à natureza sejam o grande chamariz da localidade, os termos "agência", "estrutura" e "restaurante" indicam a importância de empreendimentos de apoio à prática turística para que tal atividade seja empreendida de modo satisfatório no território sob análise.

A transcrição a seguir, portanto, perfaz um "comentário típico" extraído da página do TripAdvisor e ilustra as principais inferências e constatações anteriormente: "Passeio maravilhoso, com trilha em meio à mata, com a apreciação de rios, riachos e cachoeiras incríveis. O restaurante oferece uma comida caseira, rústica, bem de fazenda. Amei".

Deve-se destacar que a palavra "Bonito", que aparece com ênfase na nuvem de palavras, é mais alusiva à cidade sob análise e não às características dos atrativos. Para particularizar os atrativos turísticos do território, os termos mais utilizados foram "ótimo", "lindo" e "maravilhoso", sendo inclusive precedidos, em muitas circunstâncias, dos advérbios "super" e "muito" (retirados, por opção dos pesquisadores que subscrevem este artigo, da nuvem de palavras).

Com o propósito de compreender o modo como as palavras relacionam-se umas com as outras dentro dos textos dos comentários na página do TripAdvisor, elaborou-se a análise de similitude (Figura 2), que cria clusters de palavras, separados por cores, as quais aparecem de modo recorrente nos textos (mais de 20 vezes) e que se relacionam mutuamente.

Com os clusters de palavras (essas formas geográficas de cores diferentes na Figura 2), percebe-se que o termo "muito", especificamente, no cluster de cor amarela, é normalmente utilizado em conjunto com o termo "bom" (sendo superlativo deste último termo), numa dinâmica em que essas duas palavras nutrem forte relação, por sua vez, com "guia", "peixe", "maravilhoso", "fazenda", "local" e "estrutura". 
Figura 2: Análise de similitude dos termos mais fortemente relacionados nos textos

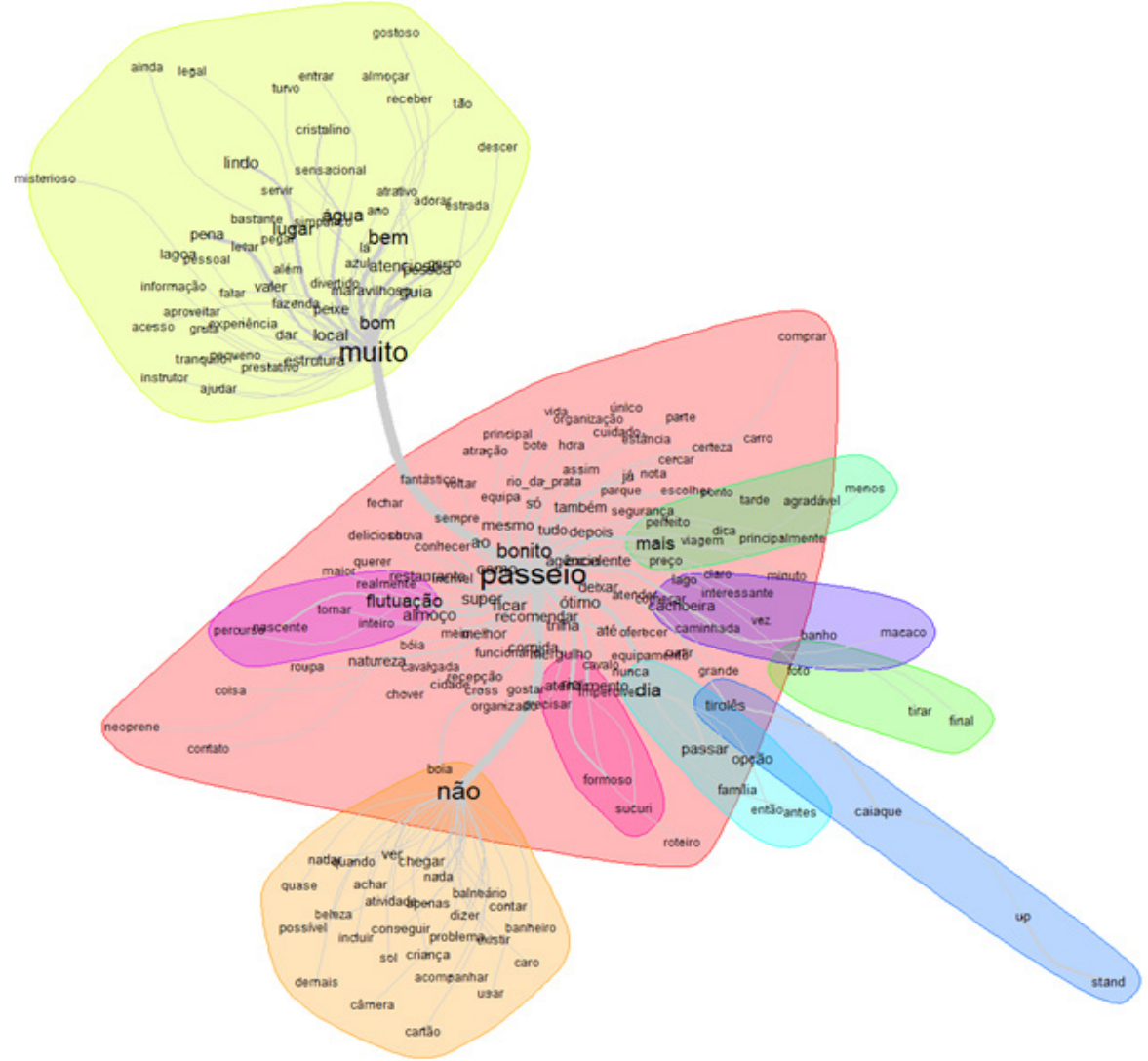

Fonte: Elaborada pelos autores a partir dos dados da pesquisa

Outras constatações que a Figura 2 permite, ainda no cluster com o termo "muito" em destaque, referem-se à proximidade entre "água" e "cristalino", "lugar" e "lindo", além de "aproveitar" e "experiência".

Em síntese, o cluster sob análise permite inferir que, a partir dos comentários da página do TripAdvisor analisados no presente estudo, os atributos relativos aos aspectos físicos do destino turístico de Bonito (ou seja, os detalhes gerais do território), além de atributos comportamentais do guia turístico, são "enxergados" pelos turistas numa perspectiva positiva, uma vez que a "raiz" do presente conjunto de palavras são os termos "muito" e "bom".

Em outra área da Figura 2, há um cluster cujo destaque é o termo "passeio". Em suma, este cluster nutre ligações com outros oito grupos menores de palavras. Um desses agrupamentos menores reúne as palavras "flutuação", "nascente" e "percurso", caracterizando os passeios de flutuação e contemplação da fauna e da flora subaquáticas dos rios; enquanto os verbetes "cachoeira", "banho" e "caminhada", em um cluster específico, representam outro tipo de passeio, este último mais ligado à ideia de contemplação e banho. Ademais, na seara dos passeios ligados à ideia de aventura, estão os termos "tirolesa", "caiaque" e "stand-up", que também formam um cluster.

Os termos "perfeito", "tarde" e "agradável", em um mesmo agrupamento, indicam aspectos relativos ao período do dia e às percepções sensoriais inerentes ao passeio, elementos hedônicos retratados por Wu, Wall e Pearce (2014); ao passo que os verbetes "opção" e "família" revelam especificidades relativas às companhias com as quais os passeios são feitos. 
Chama a atenção, na análise de similitude, a existência de um cluster cujo foco é a palavra "não", que por sua vez se relaciona a termos tais como "câmera", "criança" e "cartão". Em suma, tal cluster ilustra um conjunto de recomendações, nos comentários dos turistas no TripAdvisor, acerca de restrições para que as experiências turísticas nos atrativos de Bonito sejam maximizadas, como descritas por Munar e Jacobsen (2014), além de Chung \& Koo (2015). O trecho a seguir ilustra, em grande medida, essas perspectivas: "Quem não possuir ou se propuser a alugar uma câmera à prova da água, ficará sem registro do passeio".

Para além dos aspectos pontuados, elaborou-se também, no âmbito do presente artigo, o dendograma (Figura 3), que permite dividir as palavras em categorias de termos mais fortemente correlacionados, com a respectiva indicação do percentual de ocorrência das palavras de uma mesma categoria, no corpus textual analisado no estudo. Em suma, percebe-se, a partir do dendograma, que o corpus textual foi dividido em duas grandes categorias, sendo que uma delas, em específico, foi subdividida em quatro ramificações.

Nota-se, com base no dendograma, que a classe 5 é a terceira maior, com 23,4\% das ocorrências, sendo a menos correlacionada com as demais classes de palavras, sobretudo por aglutinar termos alusivos ao "pré-passeio", ou seja: a classe em tela ilustra questões referentes ao momento em que o turista prepara o roteiro, em agências de turismo, estabelecendo, portanto, interações com os atendentes desses estabelecimentos.

Figura 3: Dendograma do corpus textual analisado

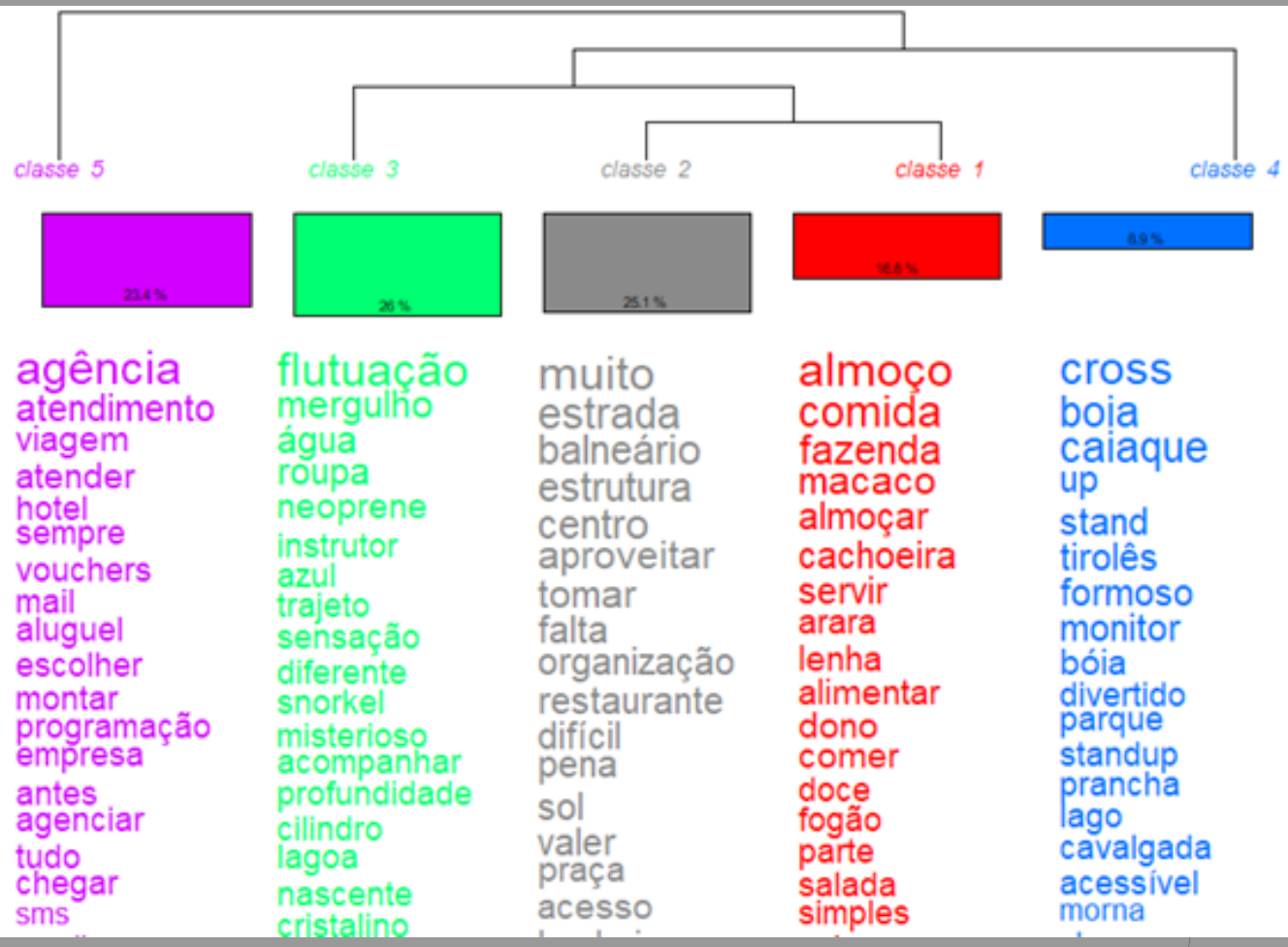

Fonte: Elaborada pelos autoresa a partir dos dados da pesquisa 
Percebe-se, ao se refletir um pouco mais detidamente acerca dos termos que compõem a classe 5, que tal categoria de palavras ilustra uma aparente contradição no comportamento do chamado "turista 2.0": apesar de esse turista ser altamente "conectado", inclusive a ponto de captar informações na internet e publicar, on-line, as suas percepções, ainda assim essas pessoas fazem questão de interagir com agências de turismo, valorizando os atributos comportamentais dos atendentes desses estabelecimentos, conferindo às agências a tarefa de montar o roteiro dos passeios em Bonito. O trecho a seguir ilustra, em boa medida, a supracitada inferência: "Super recomendo! Montaram [na agência de turismo de Bonito] nosso roteiro como queríamos, com passeios variados, apesar da estadia curta na cidade".

As classes 1 e 2 do dendrograma têm forte relação entre si e abordam aspectos alusivos ao apoio e à infraestrutura dos atrativos, do centro da cidade de Bonito, além dos atributos relacionados à alimentação.

Um fato interessante remonta à constatação de que, a despeito de a classe 1 reunir termos alusivos à alimentação, nota-se que não há verbetes que remontem a algum prato típico e/ou a alguma forma de preparo culinário peculiar do destino turístico. Tal aspecto ilustra a perspectiva de que Bonito, a despeito de ser um relevante destino de ecoturismo, ainda não conseguiu desenvolver a gastronomia típica como atrativo turístico, ou mesmo como segmento de apoio às principais ofertas turísticas do território.

Por fim, as classes 3 e 4, embora estejam distantes uma da outra, trazem atributos relacionados aos passeios turísticos em si. Em síntese, a classe 3 é alusiva a atributos dos passeios de flutuação, ao passo que a classe 4 relaciona-se com detalhes dos passeios de boia-cross e aventura. Percebe-se que ambas as classes revelam percepções distintas entre si: enquanto os turistas que apreciam passeios de flutuação têm como perspectiva a palavrachave "sensação", os turistas com predileções relacionadas aos passeios de aventura têm como perspectiva a ideia de "diversão". De todo modo, em ambos os casos, a presença do responsável por conduzir o passeio foi muito citada, com a presença das palavras "instrutor" e "monitor", conforme consta no relato: "Pela manhã fizemos dois passeios boia-cross, foi maravilhoso, os monitores são muito bons, atenciosos, cuidadosos. É muito divertido".

Por fim, elaborou-se, ainda, no âmbito do presente estudo, a Análise Fatorial de Correspondência (AFC) (Figura 4), que tem como perspectiva cotejar as relações e as inferências realizadas a partir da análise de similitude e do dendograma.

Percebe-se, a partir de uma avaliação da figura relativa à AFC, que houve a criação de quatro grandes grupos de temas: no quadrante superior direito há palavras relativas aos passeios de aventura (tais como boia-cross e caiaque); no centro há os aspectos relativos aos serviços de alimentação; no quadrante inferior, nota-se a presença de verbetes alusivos à contemplação e ao contato com a natureza (tais como os passeios de flutuação); por fim, no quadrante superior esquerdo, percebe-se um conjunto de palavras alusivas às características dos serviços oferecidos nas agências de turismo de Bonito. 
Figura 4: Análise Fatorial de Correspondência (AFC) do corpus textual coletado

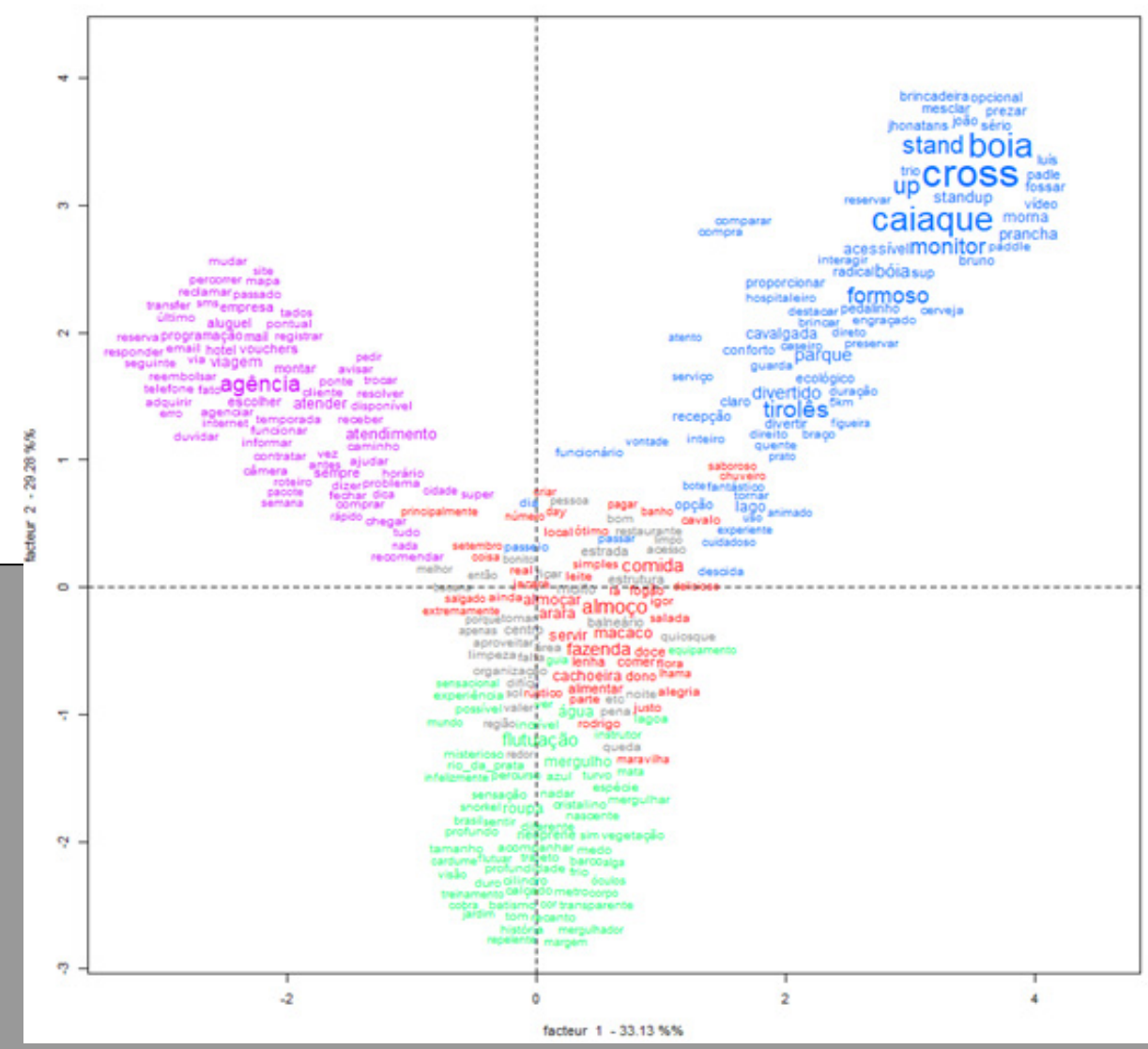

Fonte: Elaborada pelos autores a partir dos dados da pesquisa

Portanto, verifica-se que a AFC sugere uma divisão do corpus textual a partir de uma lógica próxima àquela discutida na análise de similitude e dendograma, o que faz com que as ferramentas em tela possam ser usadas de modo complementar, nos estudos que se valham do software Iramuteq na análise de informações textuais.

\section{CONSIDERAÇÕES FINAIS}

Percebeu-se que o TripAdvisor se revelou uma fonte para a redução de incertezas quanto ao destino turístico (Handel \& Schwartzstein, 2018). Em suma, tal plataforma municia o turista 2.0 com resenhas críticas, dicas, sugestões, fotos e opiniões, que podem interferir em seu processo de decisão (Fino et al., 2013; Noti, 2013; Leung et al., 2013). Essa plataforma permite ainda o compartilhamento de percepções e experiências com outras pessoas, pressionando as organizações por melhorias - caso existam aspectos negativos, passíveis de aprimoramento (Munar \& Jacobsen, 2014; Chung \& Koo, 2015). Não obstante, quais os atributos mais relevantes valorizados por turistas que teceram comentários, na página on-line do TripAdvisor, acerca dos atrativos turísticos visitados em Bonito/MS?

Constatou-se, no âmbito do presente estudo, ao se analisar as informações decorrentes dos comentários, no site do TripAdvisor, acerca de atrativos turísticos de Bonito/ MS, que os turistas valorizam os atributos principalmente relacionados a: 
- Características gerais dos atrativos turísticos, com foco para detalhes acerca das "práticas turísticas" que podem ser empreendidas no território: percebeu-se, ao longo da análise de resultados do presente artigo, que os turistas referem-se corriqueiramente às atividades com as quais se envolveram no território, o que fez com que os termos "flutuação", "boia-cross", "tirolesa" e "caiaque" - só para citar alguns poucos exemplos fossem corriqueiros no corpus textual considerado no presente estudo. Ademais, os turistas, ao se referirem a especificidades de como foram suas experiências turísticas em Bonito, constantemente realçaram detalhes da natureza e beleza cênica do destino (os termos "água", "macaco", "arara" e "cachoeira" ilustram essa perspectiva). Por fim, vale registrar ainda que, nos comentários dos turistas, também foram constantes as menções a aspectos experienciais e sensoriais, sobretudo nos "passeios" realizados no destino (os termos "aventura" e "sensação" corroboram, em boa medida, tal inferência).

- Aspectos relacionados à qualidade do atendimento nos equipamentos de apoio ao turismo no destino sob análise: constatou-se, ao longo das discussões conduzidas no presente artigo, que os turistas valorizam sobremaneira os detalhes do atendimento, sobretudo nas agências de turismo e ao longo dos "passeios" (neste último caso, o foco é o comportamento dos guias de turismo). Em suma, a ênfase da palavra "atendimento", no corpus textual analisado neste estudo, corrobora com a supracitada perspectiva.

- Detalhes da alimentação no destino turístico sob análise: sobre não terem sido detectadas referências a alimentos específicos e/ou formas de preparo típicas do território de Bonito (o que sugere que o destino não possui ênfase no turismo gastronômico), ainda assim as palavras "almoço" e "comida" foram significativas no corpus textual analisado, o que sugere que o turista dá destaque e, portanto, valoriza tais aspectos.

- Especificidades do território no qual se localizam os atrativos turísticos do destino: na investigação que envolveu a análise dos comentários dos turistas que visitaram Bonito, percebeu-se um conjunto de menções às belezas naturais da localidade, além de referências ao "centro" e à "praça" principal da cidade de Bonito. Desta feita, nota-se que o turista valoriza também aspectos do entorno do atrativo turístico que efetivamente visita, a ponto de considerar tais detalhes nos comentários que tece nas páginas on-line.

Assim sendo, avaliando-se as principais constatações sumarizadas, percebe-se que o presente artigo "alinha-se" com o escopo dos textos consultados no referencial teórico do estudo, na medida em que o corpus textual considerado nesta investigação corrobora com a importância das especificidades dos atrativos, dos detalhes do atendimento dos colaboradores, além das características do território como atributo sobremaneira valorizado pelos turistas.

Percebe-se que a contribuição do presente estudo está em destacar, para além dos atributos supracitados, a importância da alimentação como um elemento valorizado pelos consumidores, a despeito de, em muitas circunstâncias, o destino turístico sob análise não ser focado na perspectiva do turismo gastronômico (em suma, este é o caso de Bonito, cujo foco são atividades relacionadas ao ecoturismo).

Vale ainda ressaltar que o presente estudo apresenta implicações de caráter gerencial para os stakeholders ligados à atividade turística dos territórios. Em suma, a partir dos principais resultados deste estudo, percebe-se que é profícuo, por parte do segmento 
turístico, enfocar nos seguintes atributos como subterfúgios para as estratégias de marketing e comunicação com os turistas: (a) características dos atrativos turísticos com foco para o caráter experiencial e hedônico do "contato" com tais atrativos; (b) qualidade dos serviços oferecidos e do atendimento nos atrativos e nos demais empreendimentos de apoio ao turismo no território; (c) qualidade e diversidade da alimentação e, portanto, da gastronomia da localidade; e (d) particularidades do território, que podem agregar importantes elementos nas experiências turísticas no destino em análise. Resumindo-se, nota-se que a ênfase nos supracitados aspectos pode contribuir para que os empreendimentos do trade turístico dos destinos possam "entregar" uma proposta de valor mais aprimorada aos visitantes.

Destaque-se ainda, por ser oportuno, que o presente artigo ainda possui significativas contribuições teóricas e empíricas para os estudos na área de turismo, na medida em que apresenta a netnografia e, mais especificamente, o software Iramuteq como potente ferramenta para a análise do comportamento de pessoas (turistas) em ambientes virtuais.

Quanto ao uso do Iramuteq, em específico, faz-se necessário ponderar o caráter inédito do presente estudo, que, de modo pioneiro, posiciona-se como uma das primeiras referências que se valem de tal ferramenta de análise de dados textuais para a condução de investigações na área do turismo. São profícuas, portanto, novas investigações que usem o Iramuteq para a análise do fenômeno social do turismo, com base em informações textuais provenientes de fontes as mais diversas possíveis, inclusive aquelas disponíveis na internet.

É crucial frisar que o presente estudo, apesar de trazer importantes insights e inferências, não teve a pretensão de ser conclusivo e paradigmático. Novos estudos e reflexões, que considerem atrativos turísticos de outros territórios (para além de Bonito/MS e do Brasil, portanto); outros stakeholders do segmento turístico, como hotéis e restaurantes; ou que considerem premissas metodológicas e epistemológicas diferentes daquelas adotadas no presente estudo, seriam esforços interessantes para que se possa compreender, de modo um pouco mais amplo, as dinâmicas do comportamento do consumidor no âmbito do turismo contemporaneamente.

\section{REFERÊNCIAS BIBLIOGRÁFICAS}

Adade, D. R., Barros, D. F. \& Costa, A. S. M. (2018). A Netnografia e a Análise de Discurso Mediada por Computador (ADMC) como Alternativas Metodológicas para Investigação de Fenômenos da Administração. Sociedade, Contabilidade e Gestão, 13(1): 86-104.

Anuar, A. N. A., Ahmad, H., Jusoh, H. \& Hussain, M. Y. (2014). The formation of tourist friendly destination in Kuala Lumpur: a qualitative study of stakeholder perspectives. Advances in Natural and Applied Sciences, 8(4): 213+.

Barbosa, L. G. M. (Coord.). (2015). Índice de Competitividade do Turismo Nacional: Relatório Brasil 2015. Brasília/DF: Ministério do Turismo. 92 p.

Botti, L.; Peypoch, N. \& Solonandrasana, B. (2007). Time and tourism attraction. Tourism Management, 29: 594-596.

Brandt, T.; Bendler, J. \& Neumann, D. (2017). Social media analytics and value creation in urban smart tourism ecosystems. Information \& Management, 54(6): 703-713.

Camargo, B. V. \& Justo, A. M. (2013). IRAMUTEQ: um software gratuito para análise de dados textuais. Revista Temas em Psicologia, 21(2): 513-518. 
Chung, N. \& Koo, C. (2015). The use of social media in travel information search. Telematics and Informatics, 32(2): 215-229.

Computer Science and Software Engineering, 3(10): 410-417.

Correia, R. R.; Alperstedt, G. D. \& Feuerschutte, S. G. (2017). O Uso do Método Netnográfico na PósGraduação em Administração no Brasil. Revista de Ciências da Administração, 19(47): 163-175.

Costello, ML.; McDermott \& Wallace, R. (2017). Netnography: Range of Practices, Misperceptions, and Missed Opportunities. International Journal of Qualitative Methods, 16: 1-12.

Cox, C.; Burgess, S.; Sellitto, C. \& Buultjens, J. (2009). The role of user-generated content in tourists' travel planning behavior. Journal of Hospitality Marketing \& Management, 18(8): 743-764.

Duffy, A. (2016). Who needs trust when you know everything? Dealing with information abundance on a consumer-review Web site." First Monday, 21(7).

Fino, E. R.; Martín-Gutiérrez, J.; Fernández, M. D. M. \& Davara, E. A. (2013). Interactive Tourist Guide: Connecting Web 2.0, Augmented Reality and QR Codes. Procedia Computer Science, 25: 338-344.

Handel, B. \& Schwartzstein, J. (2018). Frictions or Mental Gaps: What's Behind the Information We (Don't) Use and When Do We Care? Journal of Economic Perspectives, 32(1): 155-178.

He, W.; Wang, F. K. \& Akula, V. (2017). Managing extracted knowledge from big social media data for business decision making. Journal of Knowledge Management, 21(2): 275-294.

Jablonska, M. R. (2017). Modern Consumer in Cyberspace: Internet and Psychology Approach. Foundations of Management, 9(1): 111-122.

Jacobsen, J. K. S. \& Munar, A. M. (2012). Tourist information search and destination choice in a digital age. Tourism Management Perspectives, 1: 39-47.

Jiménez, F. S. (2012). El turista 2.0 como receptor de la promoción turística: estrategias lingüísticas e importancia de su estudio. Pasos - Revista de Turismo y Patrimonio Cultural, 10(4): 143-153.

Klein, F. M.; Escandolhero, J. P. O.; Lucchese, N. R.; Mercante, M. A.; Fávero, S. \& Rodrigues, S. C. (2011). Educação ambiental e o ecoturismo na serra da Bodoquena em Mato Grosso do Sul. Revista Sociedade \& Natureza, 23(2): 311-321.

Kolb, D. \& Thach, L. (2016). Analyzing German winery adoption of Web 2.0 and social media. Journal of Wine Research, 27(3): 226-241.

Kozinets, R. V. (2002). The field behind the screen: using netnography for marketing research in online communities. Journal of Marketing Research, 39(1): 61-72.

Kozinets, R. V. (2014). Netnografia: realizando pesquisa etnográfica online. Porto Alegre: Penso Editora.

Leiper, N. (1990). Tourist Attraction Systems. Annals of Tourism Research, 17: 367-384.

Leung, D.; Law, R.; Hoof, H. \& Buhalis, D. (2013). Social media in tourism and hospitality: a literature review. Journal of Travel \& Tourism Marketing, 30(1-2): 3-22.

Malthouse, E. C.; Haenlein, M.; Skiera, B.; Wege, E. \& Zhang, M. (2013). Managing customer relationship in the social media era: introducing the social CRM house. Journal of Interactive Marketing, 27(4): 270-280.

Manosso, F. C.; Bizinelli, C.; Abrahão, C. M. S. \& Gândara J. M. G. (2015). Os atrativos turísticos de Curitiba-PR: Uma perspectiva através do Guia Brasil Quatro Rodas. Revista Brasileira de Pesquisa em Turismo, 9(1): 97-120.

Mariani, M. A. P.; Barboza, M. M. \& Arruda, D. O. (2012). Elementos determinantes de la satisfacción del consumidor de servicios turísticos. Estudios y Perspectivas en Turismo, 21(5), 1244-1261.

Marujo, N. (2012). Imágen y promoción de los destinos turísticos en Internet: el caso de los municipios de la Isla Madeira. Estudios y Perspectivas en Turismo, 21(4), 825-837.

Medeiros, M.; Nascimento, D. S. C.; Ferreira, L. V. F. \& Dantas, A. S. (2018). Imagen del destino 
Natal, Brasil: un análisis a partir del contenido generado por los usuarios en Tripadvisor. Estudios y Perspectivas en Turismo, 27(3): 533-549.

Mellinas, J. P.; María-Dolores, S. M. M. \& García, J. J. B. (2016). El uso de redes sociales por los hoteles como indicativo de gestión eficiente. Tourism \& Management Studies, 12(2): 78-83.

Miranda Júnior, N. S.; Sousa, P. H. R. \& Demo G. (2018). Análise do composto de marketing em empresas de turismo: um estudo bibliométrico. Revista Turismo - Visão e Ação, 20(2): 324-342.

Mkono, M. (2012) A netnographic examination of constructive authenticity in Victoria Falls tourist (restaurant) experiences. International Journal of Hospitality Management, 31(2): 387-394.

Mondo, T. S.; Fiates, G. G. S. (2016). Atributos de la calidad de servicios en atractivos turisticos: Un estudio netnográfico en el uso del protocolo TOURQUAL. Estudios y perspectivas en turismo, 25(2): 124-142.

Munar, A. M. \& Jacobsen, J. K. S. (2014). Motivations for sharing tourism experiences through social media. Tourism Management, 43: 46-54.

Mustelier-Puig, L. C.; Anjum, A. \& Ming X. (2018). Interaction quality and satisfaction: an empirical study of international tourists when buying Shanghai tourist attraction services. Cogent Business e Management, 5(1): 1-20.

Noti. E. (2013). Web 2.0 and the its influence in the tourism sector. European Scientific Journal, 9(20): 115-123.

Obeidat, Z. M. I.; Xiao, S. H.; Iyer, G. R. \& Nicholson, M. (2017). Consumer Revenge Using the Internet and Social Media: An Examination of the Role of Service Failure Types and Cognitive Appraisal Processes. Psychology \& Marketing, 34(4): 496-515.

OTEB - Observatório do Turismo e Eventos de Bonito/MS. (2017). Anuário Estatístico do Turismo de Bonito - Ano Base 2017. Bonito/MS: Convention \& Visitors Bureau.

Patel, K. (2013). Incremental journey for World Wide Web: Introduced with Web 1.0 to recent Web 5.0 - a survey paper. International Journal of Advanced Research in Computer Science and Software Engineering, 3(10): 410-417.

Patton, M. Q. (2002). Enhancing the quality and credibility of qualitative analysis. In: Patton, M. Q. (Ed.). Qualitative research and evaluation methods. $3^{\text {rd }}$ ed. Newbury Park: Sage Publications, pp. 541-588.

Pearce, P. L. \& Wu M. Y. (2014). Tourists' Evaluation of a Romantic Themed Attraction: Expressive and Instrumental Issues. Journal of Travel Research, 55(2): 220-232.

Polivanov, B. B. (2013). Etnografia virtual, netnografia ou apenas etnografia? Implicações dos conceitos. Revista Esferas, 2(3): 61-71.

Schuman, D. L., Lawrence, K. A. \& Pope, N. (2018). Broadcasting War Trauma: An Exploratory Netnography of Veterans' YouTube Vlogs. Qualitative health research, 29(3): 357-370.

Silva, S. A. (2015). Desvelando a Netnografia: um guia teórico e prático. Intercom - Revista Brasileira de Ciências da Comunicação, 38(2): 339-342.

Soava, G. (2015). Development prospects of the tourism industry in the digital age. The Young Economists Journal / Revista Tinerilor Economisti, 12(25), 101-116.

Souza, M. A. R.; Wall, M. L.; Thuler, A. C. M. C.; Lowen, I. M. V. \& Peres, A. M. (2018). O uso do software IRAMUTEQ na análise de dados em pesquisas qualitativas. Revista da Escola de Enfermagem da USP, 52: 1-7.

Subhiksu, I. B. K.; Ardika, I. W. \& Madiun, I. N. (2015). Museums as cultural tourism attractions in Ubud Bali Indonesia. International Journal of Scientific \& Engineering Research, 6(10): 278-285.

Tavakoli, R. \& Mura, P. (2018). Netnography in tourism - Beyond Web 2.0. Annals of Tourism Research, 73: 190-192.

Toledano, M. (2017). Emergent methods: using netnography in public relations research. Public Relations Review, 43(3): 597-604. 
Travesi, C. (2017). The politics of knowledge as a tourist attraction. Annals of Tourism Research, 66: 130-139.

TripAdvisor. (2018). "Sobre o TripAdvisor." Disponível em: <https://tripadvisor.mediaroom.com>. Acesso em: 20 de setembro de 2018.

Wirtz, B. W.; Schilke, O. \& Ullrich, S. (2010). Strategic Development of Business Models: Implications of the Web 2.0 for Creating Value on the Internet. Long Range Planning, 43(2-3): 272-290.

Wu, M. Y.; Wall, G. \& Pearce, P. L. (2014). Shopping experiences: International tourists in Beijing's Silk Market. Tourism Management, 41: 96-106.

Xiang, Z.; Du, Q.; Ma, Y. \& Fan, W. (2017). A comparative analysis of major online review platforms: Implications for social media analytics in hospitality and tourism. Tourism Management, 58: 51-56.

Yilmaz, E. S. (2017). Analyzing the Effects of Comments on Social Networking Sites on Consumer Purchasing Decision Process. International Journal of Academic Research in Business and Social Sciences, 7(6): 140-162.

Zucco, F. D.; Pereira, M. L.; Limberger, P. F.; Falaster C. D. (2018). Avaliação da imagem de um destino turístico no Instagram. Revista Turismo - Visão e Ação, 20(3): 490-499.

\section{CONTRIBUIÇÃO DE CADA AUTOR NA ELABORAÇÃO DO ARTIGO:}

MAURÍLIO BARBOSA DE OLIVEIRA DA SILVA: Coleta e sistematização das informações necessárias para o artigo, na página on-line do TripAdvisor. Análise de dados, usando o software Iramuteq. Busca de referenciais teóricos em fontes especializadas (Scopus, Web of Knowledge, Scielo e Google Acadêmico). Redação do artigo.

DYEGO DE OLIVEIRA ARRUDA: Análise de dados, usando o software Iramuteq. Busca de referenciais teóricos em fontes especializadas (Scopus, Web of Knowledge, Scielo e Google Acadêmico). Redação do artigo.

Álvaro Gabriel Romero de Souza: Coleta e sistematização das informações necessárias para o artigo, na página on-line do TripAdvisor. Análise de dados, usando o software Iramuteq. Busca de referenciais teóricos em fontes especializadas (Scopus, Web of Knowledge, Scielo e Google Acadêmico).

MILTON AUGUSTO PASQUOTTO MARIANI: Análise de dados, usando o software Iramuteq. Redação do artigo. Orientação do grupo de pesquisa que trabalhou na proposta do artigo. 